\title{
University physics students' motivations and experiences in informal physics programs
}

\author{
Claudia Fracchiolla, ${ }^{1}$ Simone Hyater-Adams, ${ }^{2}$ Noah Finkelstein, ${ }^{3}$ and Kathleen A. Hinko ${ }^{1}$ \\ ${ }^{1}$ JILA AMO Physics Frontier Center, University of Colorado Boulder, 440 UCB, Boulder, CO, 80309 \\ ${ }^{2}$ ATLAS Institute, University of Colorado Boulder, $320 \mathrm{UCB}$, Boulder, CO, 80309 \\ ${ }^{3}$ Department of Physics, University of Colorado Boulder, 390 UCB, Boulder, CO, 80309
}

\begin{abstract}
Substantial resources are directed toward public engagement by the physics community, but there is still much to understand about physicists' initial motivation for involvement, their experiences and their reasons for sustained participation. We use motivation theory as a lens to investigate the factors that contribute to physics students' decisions to participate in informal science programs. We conducted surveys and interviews with university students that volunteered in an afterschool physics program for K-12 students. Interviews were analyzed using content analysis. Findings indicate that previous participation in informal activities, attitudes towards engaging with the community, and recognition from peers are common themes in university students' initial reasons for involvement. The emergent themes of a positive experience and the enjoyment of sharing physics are related to students' persistence in the program.
\end{abstract}

\section{INTRODUCTION}

While many physics departments have a tradition of facilitating outreach activities, these activities are often considered peripheral to the main function of the department. Some faculty view these informal learning activities as only benefiting public audiences, and they may have concerns about the amount of time that students who participate in them spend away from their physics research. At the same time, there is increasing pressure from funding agencies for basic scientific research to have broader impact through outreach to the public. For instance, the National Science Foundation (NSF) mandates that proposals include not only how their research will generally benefit society at large but also how it will affect society via education, inclusion of underrepresented groups, and outreach programs that promote public discussion of research findings [1]. Thus, although some physicists might be feeling pressured to engage in informal learning, they may not see it as useful except as a means to an end for grant funding.

In this study, we investigate how physicists' motivation to participate in informal physics is impacted as part of a particular model of community engagement that is mutually beneficial for both the community and participants [2]. Prior work shows that outcomes for physicists who participate in informal physics programs are improved scientific communication skills [3] and gaining teaching experience [4]. Additional research in chemistry [5] indicates that another way engaging in outreach activities benefits academics is by reinforcing their excitement about science. Here we examine motivational outcomes for university physics students that participate in a particular model of informal physics that engages $\mathrm{K}-12$ audiences in an afterschool program. More specifically, we investigate possible changes in motivation (from extrinsic to intrinsic) after participation in informal science programs and if those changes could be attributed to cultivation of motivation through opportunities that facilitate the improvement of the self.

\section{BACKGROUND \& FRAMEWORK}

Previous research [6],[7] has identified predictors for participation in informal science programs that include: previous participation, belief that it is important to do outreach, whether scientists feel capable of participating, and how much they perceive their colleagues are participating in outreach activities. On the other hand, some factors that did not predict participation were: career recognition, sustainability for their own research (even though scientists believe outreach is important, they still do not intend to participate themselves), what others think, and time and money constraints [6], [8]. From these studies, we have some idea of which scientists participate in informal programs and what influences their decisions. The impact, however, of informal teaching and learning experiences on participants' motivations has not been examined in the physics context. Most of the work has looked broadly across science and math departments and focused on faculty. In this work, we situate our investigation within physics and we focus on university students who participate in informal physics programs for public audiences.

We employ motivation theory to understand what makes physics students engage in informal physics. Hull's drive theory of motivation [9] suggests that all motivation arises from some biological need. As those needs are satisfied a positive attitude towards the action that provided satisfaction for the need will be reinforced, which leads to a positive motivation to pursue that action in the future. Researchers use motivation to study the process that initiates behaviors and classify two different categories: extrinsic and intrinsic. Extrinsic motivation refers to the motivation created by external factors; the individual engages in an activity as the means to an end and expects a reward at completion of the task [10]. Intrinsic motivation is that which determines an individual's engagement in activity for the pure reason of pleasure and satisfaction, without mediating effects of external rewards or pressures [11].

There are three main factors that impact intrinsic motivation [12]: autonomy, competence, and relatedness. Auton- 
omy is seen as the individual's perceived control over engagement in a task [13]. If scientists believe it is their decision and an option, it is more likely that they will participate in outreach. Competence refers to the desire to achieve mastery and feel accomplished in interactions with the environment [14]. The more people believe they are competent, then the more intrinsically motivated they are to participate in an activity and perform well in it [15]. A previous study [6] shows that scientists' beliefs about their ability to perform outreach well (such as having prerequisite public communication skills) is one of the biggest predictors of participation. Finally, relatedness is defined as the desire to belong to a group or community [16]. Previous research [6] has indicated that is not so much what others think, but the perception of what others are doing that predicts scientists' participation in outreach activities; i.e. if others are doing it, I should do it to.

\section{CONTEXT \& METHODS}

We investigate physicists' motivations for participation in outreach in the context of an informal physics program: Partnerships for Informal Science Education in the Community (PISEC) at the University of Colorado Boulder [17]. PISEC is a weekly afterschool program that brings physicists and $\mathrm{K}$ 12 students together to do hands-on physics activities through partnerships with community organizations. It is based on a model for educational afterschool environments designed for intergenerational work on exploratory leading activities [18]. In PISEC, physics undergraduates, graduate students, and post-docs, known as university educators (UEs), volunteer once a week to work with children afterschool.

UEs are recruited through emails, word-of-mouth, and informational sessions during the first few weeks of each semester. They sign up for a particular PISEC site and then spend 5-6 hours in training sessions to prepare them to work with youth. The content of the training sessions include performing the physics activities and providing feedback, creating animated movies explaining research topics to children, and an interactive workshop on issues of diversity and pedagogy. After the training period, UEs work with children for an hour per week for 8-10 weeks at the PISEC sites. This frontend training is designed to keep the total time commitment each week for the UEs to around two hours, including travel to and from sites. At the end of the semester, the kids come to campus for a field trip, during which UEs give lab tours, speak on life as a physicist, and perform demonstrations.

We find that in PISEC there are a sizable number of volunteers each semester. From 2011-2014, there were 71 total volunteers with an average of 20 per academic semester. Of these total volunteers, $55 \%$ were graduate students, $35 \%$ were undergraduates, and $10 \%$ were post-docs or staff. In total, 25 physics research groups on campus were represented. PISEC also has a significant retention rate: one in three UEs volunteer a second semester, with one in four volunteering three or more semesters.
For a voluntary program with a repeated time commitment, where UEs are managing classes, lab work, and in some cases teaching or learning assistant positions, the numbers for participation and retention are fairly robust, especially for graduate students. Demonstrating high levels of volunteerism (through each semester and from semester to semester) would seem to indicate that the program has good recruitment strategies, while high levels of retention would seem to indicate that UEs had a positive experience with the program and found that experience worthwhile.

To understand these participation levels, we investigate the motivation of UEs to volunteer as well as the UEs' experiences in the program that may affect their motivation. To do this, we asked first time volunteers to complete a pre-survey at the beginning of the semester prior to the training or the start of the afterschool sessions with children. UEs were required to respond to the question "Why do you want to participate in PISEC?" in an open response format. At the end of the semester after the completion of the afterschool sessions, all UEs were given a post-survey where they were asked the same question but were given a list of options to choose from, including the opportunity to write in their own response. The options given were chosen from the common responses UEs gave during the pre-survey. The reason to do this was to minimize the time commitment for UEs at the end of the semester. Forty-two pre-surveys and 67 post-surveys were collected. There were more post-surveys due to returning volunteers. Pre-survey responses were coded based on the options from the post-survey, with specific attention paid to any responses that did not clearly align with the categories. To understand UEs' motivations and experiences in PISEC in more detail, interviews were conducted $(n=13)$ with UEs from the most recent year of the program (There were no UEs' interviews from previous years of the program). These interviews were coded using content analysis to determine emergent themes and discussed with the lens of motivation theory.

\section{MOTIVATION TO PARTICIPATE IN PISEC}

From the pre-survey results (Figure 1), the top reason UEs gave for volunteering was to gain a teaching opportunity. These responses are described by some UEs in their interviews. Several UEs talk about the teaching opportunity in light of their applications for the NSF Graduate Research Fellowship, saying: "I needed an outreach thing for NSF," and "Also, when I applied for the NSF last year they said I needed more outreach things and I was like well, you know, that is a good point." We classify these explanations as extrinsically motivated since teaching is being viewed as a means to an external reward for the UE.

The second most popular reason that UEs gave was to have fun with kids. This rationale could be considered intrinsically motivated since it is for the personal enjoyment of the UE. In interviews, UEs described hearing about PISEC by word-ofmouth, mainly through discussions with their colleagues and 


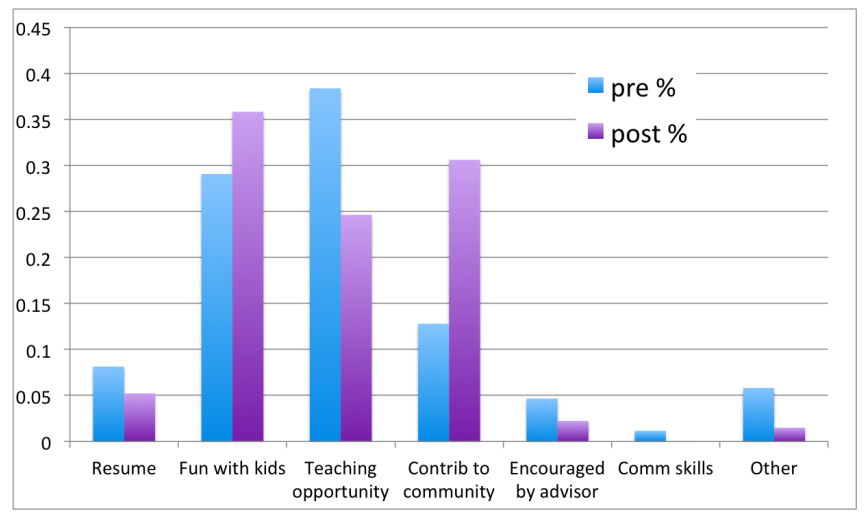

FIG. 1. Reasons that UEs choose to participate in PISEC.

classmates who had participated previously and reported positive experiences. One student explained that "My labmate did it and said it was a lot of fun. He would just go to do it every week and come back and like tell stories about what they did with the kids and playing around with lasers and it seemed fun." Another student reported: "Somebody in my office, I think [student name], joined last year for a term. She seemed to enjoy it, she thought it was cool."

An interesting factor that emerged from the interviews was that some UEs undertook a proactive search for outreach programs in which to become involved, in contrast to more passive situations like hearing about the program from colleagues or reading an informational email. When they were actively searching for outreach, PISEC was one of the activities at the University of Colorado that most appealed to people. One person even commented, "It was like one of the three reasons I wanted to come here [for grad school] is because they had a program like that." Additionally, UEs also mentioned that program reputation was important to them: "PISEC just seemed like a great organization," and "it stood out as kind of a unique opportunity."

In our data, there seems to be a change in the UEs' motivation for participation in PISEC when we compare the presurvey responses to the post-survey responses as shown in Figure 1. Initially, resume and teaching opportunities had higher percentages of responses as reasons to initially participate in outreach, but those percentages were lower at the end of the semester when UEs were asked why they would participate again. However, the reasons UEs gave to participate again were having fun with kids and contributing to community. From the comparison of the responses of the pre and post surveys it seems UEs have a tendency to initially join PISEC due to extrinsic motivations, while for continued participation the motivation seems to be driven by intrinsic reasons. To investigate what prompted those changes we interviewed UEs that had recently participated in PISEC to describe the experiences they had that would motivate them to participate again.

\section{EXPERIENCES IN PISEC}

We find two main themes in the interview data that suggest a mechanism for the shift from extrinsic to intrinsic motivation for UEs volunteering in PISEC.

\section{Sharing science}

One main theme for the UEs to join and continue participating in PISEC is the ability to "share science". Many UEs report enjoying sharing their passion for physics and getting others excited about physics:

"I just kind of forget how smart and cool kids are sometimes (laughs) and it's kind of like an exciting thing to get the chance to get [them] interested in science"

"Well, I get a lot of satisfaction out of physics. I think it's fascinating. I think other people should think it's fascinating. You know, it's something that I enjoy and when I have had the opportunity to successfully communicate and maybe teach something to somebody that they didn't know - you know, that look on somebody's face when they suddenly understand something which they never really thought that they could understand is great. Yeah. I really like sharing what has interested me so much with other people."

This theme of "sharing science" can be understood through the components of intrinsic motivation. When an individual feels accomplished (competent) in his/her interactions in the environment then his/her desire to continue to do that activity is what drives that individual's behavior. Also, sharing science is an activity that connects the participants to the physics community (relatedness). It reaffirms to them that they are part of that community, reinforcing a sense of belonging.

\section{Positive Experience}

Another important factor for UEs is having a positive experience doing outreach. This theme includes the UEs' past experiences with other informal activities, as well as their personal experience during their participation in the PISEC program. This theme emerges from nearly all of the UE interviews as influential in their interest for continued participation in informal physics:

"I'd been working in a lab for a little while already before I joined the first semester and I already knew how nice it would be to have kind of a break for a few hours every week"

"I just really enjoyed the experience, yeah. It was a lot of fun. Definitely a good way to get away for a few hours a week"

"So it was sometimes stressful because of that I was behind (referring to homework), you know. But I'd say it was only a stress inducer less than a third of the time. 
And even when the concept of going was stressful, going itself was very cathartic and nice. It was always fun...It was always a stress reliever"

An important emergent finding from the data is that PISEC provided an escape for UEs from doing lab worked and routine activities. The volunteers are still engaging in physics activity during PISEC but in a different way, and this means of engagement seems to shed a new light on their appreciation for physics; in their own words, volunteers say that going to PISEC was "refreshing" to them. We speculate that having a break from the "grind" to do PISEC may lead to increased motivation in their classwork and research.

\section{DISCUSSION}

The initial motivation for students to participate in an informal physics program and how the experiences they had in the program impacted their motivation were studied. Preliminary results indicate a change in UEs' motivations after a semester of participation in PISEC. UEs' initial motivations for participation are both extrinsic and intrinsic and align with what previous research has indicated as predictors of participation. Motivation for continued participation, however, is driven more by personal satisfaction from sharing science and contributing to the community, with less influence from external mediating means. Their experiences in choosing to participate in PISEC seem to have both increased their sense of autonomy, because they choose to come back, and also boosted their competence and sense of accomplishment, as well as their sense of belonging to a community, which may in turn reinforce their identity as physicists. Changes in motivations to participate in PISEC are evidence that interactions with the kids and other members of PISEC changes UEs' definition of self so that they give more value to intrinsically important things rather than external factors. Another reason for the shift could be that after one semester of involvement in the program, the rewards associated with extrinsic motivations will have been satisfied. Nevertheless, this change also suggests that the identity of the UEs is being impacted by the interactions and experiences they have in PISEC.

Design and facilitation of informal physics have implications in the efforts to attract more undergraduate and graduate students to pursue and persist in careers in physics, in particular students from underrepresented minorities. Recent studies show that for minority students, participating in programs that give back to their communities can be especially impactful [19]. For these students, giving back can be an important part of their identity within their STEM discipline. Implications of studies such as Estrada et al. are so strong that a research one university is creating a class for freshman students to engage in science outreach activities. Because the university believes, quoting the Director of Physics Outreach, "one of the things that they've [referring to university administrators] learned is if you want students to stay here [at the university] and be successful you need to have them feel that being a [part of the university] is an important part of their identity. And giving them experiences helps..." [20].

In future work, we plan to expand the study whether these patterns are true for other models of outreach programs, including more volunteers at different levels of their careers, as well as considering gender and ethnicity to determine the impact that participation in physics outreach activities has on their motivation and physics identities.

\section{ACKNOWLEDGMENTS}

We thank the children and adults who participate in PISEC as well as the PER group at CU Boulder. This work is supported by the JILA NSF Physics Frontier Center (\#1125844) and the NSF Advancing Informal STEM Learning award (\#1423496).
[1] http://www.nsf.gove/pubs/gpg/broaderimpacts.pdf Accessed 2012 Apr 11.

[2] Finkelstein, N. D., et al., (2008). In AIP Conference Proceedings 1064(1).

[3] Hinko, K. A., et al., (2016). Phys. Rev. PER, 12(1).

[4] Hinko, K. A., \& Finkelstein, N.D. (2012). Proc. PERC, AIP Press, Melville, NY.

[5] Cacciatore, K. L., \& Sevian, H. (2011). J. of Chem. Educ., 88(3), 248-250.

[6] Poliakoffl E, \& Webb T. L. (2007) Sci. Comm. 29(2): 242-263.

[7] Foster, et al., Science 2010, 329 (5994), 906-907

[8] Ecklund, E. H., et al., (2012). PloS one, 7(5).

[9] Hull, C. L. (1943). Principles of behavior: An introduction to behavior theory. NY: Appleton-Century-Crofts.

[10] Schunk H., et al., (2008). Motivation in education: Theory, research, and applications. NJ: Pearson.
[11] Malone, T. W. (1981). Cognitive Science, 5(4), 333-369.

[12] Deci, E. L. (1975). Intrinsic motivation. NY: Plenum

[13] Pintrich R., P., \& Schunk H., D. (1996). Motivation in education: Theory, research and applications.

[14] Harter, S. (1978). Effectance motivation reconsidered: Toward a developmental model. Human development, 21(1), 34-64.

[15] Deci, E. L. (1980). The psychology of self-determination. MA: Heath.

[16] Baumeister, R. F., \& Leary, M. R. (1995). Psychological Bulletin, 117(3), 497.

[17] http://www.colorado.edu/physics/PISEC/

[18] Cole, M. (2006). The Fifth Dimension: An After-School Program Built on Diversity. Russell Sage Foundation: New York.

[19] Estrada et al., (2011). J. Edu. Psych. 103:206-222.

[20] Interview with Director of Little Shop of Physics outreach from Colorado State University 